\title{
Pemanfaatan limbah kolam lele (clarias sp.) Sebagai pupuk organik dalam penerapan akuaponik
}

\section{Utilization of catfish (Clarias sp.) pond waste as organic fertilizer in the application of aquaponics Dimas Galang Prakosa}

\author{
Program Studi Budidaya Perikanan, Fakultas Sains dan Teknologi, Universitas Ibrahimy \\ Penulis korespondensi: Email : dimasgalang2008@gmail.com \\ (Diterima September 2021/ Disetujui Oktober 2021)
}

\begin{abstract}
The aims of this study was to determine the effect of the aquaponic system on the normalization of water quality for organic catfish cultivation, the survival rate of catfish and the growth of water spinach in the aquaponics system. The research method to be carried out is an experimental method using a completely randomized design (CRD) with different stocking densities, namely P1 (100 fish $/ \mathrm{m} 2), P 2$ (250 fish $/ \mathrm{m} 2)$, and P3 (500 fish $/ \mathrm{m} 2)$. The parameters measured were the water quality of the catfish culture media including $\mathrm{NH} 3, \mathrm{NO} 2, \mathrm{NO} 3, \mathrm{pH}$, and dissolved oxygen, as well as the survival rate of catfish and kale plant growth (plant height, number of leaves, and leaf width). The results showed that rearing catfish with an aquaponic system with Kangkung plants could stabilize water quality. Value of water quality NH3 $(0-0.1 \mathrm{ppm}), \mathrm{NO} 2(0-0.881 \mathrm{ppm}), \mathrm{NO} 3(0-$ $1.443 \mathrm{ppm}), \mathrm{pH}(6-7.8)$, and dissolved oxygen $(4.5-6.2 \mathrm{ppm})$. The survival rate was $P 1(95.2 \%)$, $P 2$ (94.3\%), P3 (89.6\%). The best growth of kale was found in the P3 treatment, namely plant height $37.2 \mathrm{~cm}$, leaf width $2.5 \mathrm{~cm}$, and number of leaves 24 strands. The results showed that the water quality was relatively stable. The higher the stocking rate, the lower the survival rate of catfish, on the other hand, the higher the stocking density, the better the growth of kale plants.
\end{abstract}

Keywords: aquaponic, Clarias sp., organic, nutrient film technique

\begin{abstract}
ABSTRAK
Tujuan dari penelitian ini adalah untuk mengetahui efek sistem akuaponik terhadap normalisasi kualitas air budidaya lele organik, tingkat survival rate ikan Lele serta pertumbuhan tanaman Kangkung pada sistem akuaponik. Metode penelitian yang akan dilakukan adalah metode eksperimen dengan menggunakan rancangan acak lengkap (RAL) dengan padat tebar berbeda yaitu P1 $\left(100 \mathrm{ekor} / \mathrm{m}^{2}\right)$, P2 (250 ekor $\left./ \mathrm{m}^{2}\right)$, dan P3 $\left(500 \mathrm{ekor} / \mathrm{m}^{2}\right)$. Parameter yang diukur adalah kualitas air media budidaya ikan Lele meliputi $\mathrm{NH}^{3}, \mathrm{NO}^{2}, \mathrm{NO}^{3}, \mathrm{pH}$, dan Oksigen terlarut, serta tingkat kelulushidupan ikan Lele dan pertumbuhan tanaman Kangkung (tinggi tanaman, jumlah daun, dan lebar daun). Hasil penelitian menunjukkan pemeliharaan ikan lele dengan sistem akuaponik dengan tanaman Kangkung dapat menstabilkan kualitas air. Nilai kualitas air $\mathrm{NH}^{3}(0-$ $0.1 \mathrm{ppm}), \mathrm{NO}^{2}(0-0.881 \mathrm{ppm}), \mathrm{NO}^{3}(0-1.443 \mathrm{ppm}), \mathrm{pH}(6-7.8)$, dan oksigen terlarut $(4.5-6.2$ ppm). Nilai survival rate P1 (95.2\%), P2 (94.3\%), P3 (89.6\%). Pertumbuhan tanaman Kangkung terbaik didapatkan pada perlakuan P3 yaitu tinggi tanaman $37.2 \mathrm{~cm}$, lebar daun $2.5 \mathrm{~cm}$, dan jumlah daun 24 helai. Hasil penelitian menunjukkan kualitas air relative stabil. Semakin tinggi pada tebar semakin rendah tingkat survival rate ikan Lele, disisi lain semakin tinggi padat tebar semakin bagus pertumbuhan tanaman Kangkung.
\end{abstract}

Kata kunci: akuaponik, Clarias sp., organik, nutrient film technique.

To Cite this Paper Prakosa, D, G., 2021 Pemanfaatan limbah kolam lele (clarias sp.) Sebagai pupuk organik dalam penerapan akuaponik. Samakia: Jurnal Ilmu Perikanan, 12 (2): 170-174 


\section{PENDAHULUAN}

Sistem teknologi akuaponik merupakan penggabungan antara sistem akuakultur dan sistem hidroponik. Dalam sistem akuakultur, sumber daya air merupakan hal yang sangat penting. Ketersediaan air secara kuantitatif maupun kualitatif merupakan prasyarat untuk dapat berlangsungnya kegiatan akuakultur. Seiring dengan makin pesatnya laju penbangunan maka salah satu konsekuensi yang harus kita hadapi adalah semakin menyusutnya sumber air, khususnya di daerah perkotaan. Padahal, air menjadi salah satu yang dapat digunakan untuk mendukung aktivitas sehari-hari manusia, di antaranya adalah untuk bidang perikanan.

Sistem teknologi akuaponik merupakan salah satu alternatif pemecahan yang dapat diterapkan dalam rangka pemecahan keterbatasan air tersebut. Di samping itu, sistem teknologi akuaponik juga mempunyai keuntungan lainnya berupa pemasukan tambahan dari hasil tanaman yang akan memperbesar keuntungan para peternak ikan. Sistem teknologi budidaya akuaponik pada prinsipnya adalah menggabungkan antara budidaya perikanan dan tanaman dalam satu wadah. Budidaya ikan merupakan sektor utama usaha agribisnis, sedangkan hasil tanaman merupakan produk sampingan yang dapat menambah keuntungan para peternak ikan.

Akuaponik merupakan kombinasi dari teknik pembesaran akuakultur dengan teknik pembesaran tanaman secara hidroponik. Teknologi akuaponik suatu sistem tanam terpadu yang menggunakan hasil perombakan bahan organik dalam budidaya ikan sebagai nutrisi bagi budidaya tanaman. Akuakulltur ikan berusaha memaksimalkan pertumbuhan ikan dalam kolam atau wadah pemeliharaan yang terbatas. Pada sistem ini jumlah ikan yang ditebar dalam jumlah yang cukup banyak dalam kolam atau wadah pemeliharaan yang terbatas sehingga memiliki tingkat kepadatan yang tinggi. Hal ini mengakibatkan tingginya tingkat limbah organik dalam air pemeliharaan ikan, sehingga menyebabkan kualitas lingkungan air akan turun dan pada akhirnya dapat meracuni ikan.

Budidaya tanaman secara hidroponik membutuhkan nufrisi dan unsur-unsur mikro yang ditambahkan dalam media tanam cair tanaman. Kebutuhan nutrisi, unsur mikro dan unsur organik tersebut dibuat dan sengaja ditambahkan agar tanaman dapat tumbuh dengan optimal. Akuaponik menggabungkan sistem akuakultur dan hidroponik yaitu dengan memanfaatkan limbah organik budidaya ikan sebagai sumber nutrisi pada budidaya tanaman. Di samping itu, akuaponik juga memanfaatkan sistem budidaya tanaman untuk membersihkan dan memurnikan air untuk budidaya ikan. Prinsip akuaponik adalah resirkulasi air, dimana air dari pemeliharaan ikan secara terus menerus dialirkan ke media tanam tanaman untuk disaring dan kembali lagi ke air pada pemeliharaan ikan.

Akuaponik memiliki beberapa keuntungan lain, selain mengoptimalkan budidaya tanaman dan ikan. Akuaponik dapat dilakukan di lahan yang sempit, dan dengan teknik resirkulasi air dapat rnengurangi pemakaian air untuk budidaya ikan, mengurangi pencemaran limbah budidaya ikan, dan memastikan ketersediaan air bersih untuk budidaya ikan. Beberapa hal yang perlu diperhatikan dalam akuaponik adalah luas lahan, jenis ikan, kepadatan ikan, jenis tanaman, media tanam, rancangan sistem akuaponik, dan parameter biotik dan lingkungan. Tujuan dari penelitian ini adalah mengetahui pengaruh efek sistem akuaponik terhadap normalisasi kualitas air budidaya lele organik serta tingkat survival rate ikan Lele, dan pertumbuhan tanaman Kangkung pada sistem akuaponik.

\section{MATERI DAN METODE}

\section{Waktu dan Tempat}

Penelitian akan dilaksanakan pada tahun 2021 dan bertempat di Laboratorium Budidaya Perairan, Fakultas Sains dan Teknologi Universitas Ibrahimy.

\section{Alat dan Bahan}

Peralatan yang digunakan dalam penelitian antar lain: wadah pemeliharaan ikan, rak pemeliharaan tanaman, pipa pvc, sambungan pipa, aerator, pompa, timer, siphon.

Bahan-bahan yang digunakan antara lain: bibit tanaman/sayuran, bibit ikan, media tanam (kerikil, arang, sabut kelapa), probiotik/pupuk organik

To Cite this Paper Prakosa, D, G., 2021 Pemanfaatan limbah kolam lele (clarias sp.) Sebagai pupuk organik dalam penerapan akuaponik. Samakia: Jurnal IImu Perikanan, 12 (2) : 170-174 


\section{Desain Penelitian}

Metode yang akan dilakukan dalam penelitian ini adalah metode eksperimen dengan rancangan acak lengkap (RAL) dengan 3 perlakuan perbedaan pada tebar ikan Lele yaitu P1 $\left(100 \mathrm{ekor} / \mathrm{m}^{2}\right)$, P2 (250 ekor $\left./ \mathrm{m}^{2}\right)$, P3 (500 ekor $/ \mathrm{m}^{2}$ yang dipadukan dengan sistem akuaponik tanaman Kangkung pada masing-masing media budidaya ikan Lele.

Variabel pengamatan yaitu kualitas air media budidaya ikan Lele meliputi $\mathrm{NH}_{3}, \mathrm{NO}_{2}, \mathrm{NO}_{3}$, pH, dan oksigen terlarut, tingkat kelulushidupan ikan Lele dan pertumbuhan tanaman Kangkung (tinggi tanaman, jumlah daun, dan lebar daun).

Pengamatan kualitas air dilakukan setiap satu minggu satu kali yaitu pada hari ke-0, hari ke-7, hari ke-14, hari ke-21, dan hari ke-28. Pengamatan survival rate dilakukan dengan menghitung jumlah ikan yang mati setiap hari dan diakhir mengkalkulasi jumlah ikan yang hidup. Pengamatan tanaman Kangkung dilakukan pada awal dan akhir masa pemeliharaan.

Penelitian ini menerapakan sistem resirkulasi Deep Flow Technique (DFT) seperti pada Gambar 3. Cara kerja sistem DFT yaitu air dipompa dari kolam menuju wadah tanaman dan menggenangi akar tanaman setebal $1-3 \mathrm{~cm}$.

\section{HASIL DAN PEMBAHASAN}

\section{Kualitas Air}

Media pemeliharaan ikan lele menjadi indikator penentu utama normalitas pertumbuhan dan kesehatan ikan. Kualitas air menjadi penentu kualitas budidaya ikan. Selama masa pemeliharan ikan lele dengan sistem akuaponik dianalisa indikator kualitas air yaitu Amonia $\left(\mathrm{NH}_{3}\right)$, Nitrit $\left(\mathrm{NO}_{2}\right)$, Nitrat $\left(\mathrm{NO}_{3}\right), \mathrm{DO}, \mathrm{pH}$, dan suhu. Pengukuran Amonia, Nitrit, Nitrat, dan oksigen terlarut dilakukan selama dua kali yaitu pada minggu pertama awal penebaran dan minggu ke-4 akhir masa pemeliharan. Pengukuran ini untuk melihat efektivitas sistem akuaponik ikan Lele dan sayuran kangkung.

Tabel 1. Data kualitas air media pemeliharaan ikan Lele sistem Akuaponik

\begin{tabular}{lcccc}
\hline Perlakuan & \multicolumn{3}{c}{ Nilai } & Acuan \\
\cline { 2 - 4 } & $\begin{array}{c}\text { P1 } \\
\left(100 \mathrm{ekor} / \mathrm{m}^{2}\right)\end{array}$ & $\begin{array}{c}\mathbf{P 2} \\
\left(250 \mathrm{ekor} / \mathrm{m}^{2}\right)\end{array}$ & $\begin{array}{c}\mathbf{P 3} \\
\left(500 \mathrm{ekor} / \mathrm{m}^{2}\right)\end{array}$ & \\
\hline $\mathrm{NH}_{3}(\mathrm{ppm})$ & $0-0.08$ & $0-0.08$ & $0-0.1$ & $\begin{array}{c}0.1 \\
(\text { Ghufron, 2010) } \\
0.05\end{array}$ \\
$\mathrm{NO}_{2}(\mathrm{ppm})$ & $0-1.512$ & $0-1.662$ & $0-1.881$ & $\begin{array}{c}\text { (Setijaningsih dan } \\
\text { Suryaningrum, 2015) } \\
20\end{array}$ \\
$\mathrm{NO}_{3}(\mathrm{ppm})$ & $0-0.471$ & $0-0.891$ & $0-1.443$ & $\begin{array}{c}\text { (Tatangindatu et al., } \\
2013)\end{array}$ \\
$\mathrm{DO}(\mathrm{ppm})$ & $4.5-6.2$ & $4.6-6$ & $4.5-6$ & $\begin{array}{c}4.4-4.6 \\
\text { (Augusta, 2016) } \\
26-31\end{array}$ \\
$\mathrm{Suhu}\left({ }^{\circ} \mathrm{C}\right)$ & $28-31$ & $28.5-31$ & $28-31.5$ & $\begin{array}{c}\text { (Mahari, 2017) } \\
6-8.5\end{array}$ \\
$\mathrm{pH}$ & $6-7.5$ & $6-7.8$ & $6-7.6$ & $\begin{array}{c}\text { (Defrizal dan Khalil, } \\
2015)\end{array}$ \\
\hline
\end{tabular}

Hasil pengukuran kualitas air pada tabel 2 masing-masing perlakuan nilai $\mathrm{NH}_{3}, \mathrm{NO}_{3}, \mathrm{DO}, \mathrm{pH}$, dan suhu secara umum berada pada kisaran normal. Berbeda dengan hasil pengukuran $\mathrm{NO}_{2}$ menunjukkan nilai pada kisaran $0-1.881 \mathrm{ppm}$ dinilai melebihi ambang batas yang disarankan untuk budidaya ikan Lele menurut Setijaningsih dan Suryaningrum, (2015) yaitu maksimal 0.05 ppm. Namun selain dari nilai ambang batas nilai NO2 0.05 ppm ikan masih terlihat normal dengan

To Cite this Paper Prakosa, D, G., 2021 Pemanfaatan limbah kolam lele (clarias sp.) Sebagai pupuk organik dalam penerapan akuaponik. Samakia: Jurnal IImu Perikanan, 12 (2): 170-174 
gerakan lincah, nafsu makan normal, warna tubuh hitam cerah, dan ikan berada pada seluruh aeral kolam. Hasil pengamatan data kualitas pada nilai $\mathrm{NH}_{3}, \mathrm{NO}_{3}, \mathrm{DO}, \mathrm{pH}$, dan suhu juga mengindikasikan adanya peran simbiosis dari pemanfaatan budidaya dengan sistem akuaponik. Budidaya ikan lele pada padat tebar.

\section{Survival rate ikan Lele}

Kualitas air yang baik akan berkorelasi dengan tingkat kehidupan ikan yang dipelihara. Pada gambar 1 terlihat tingkat kehidupan atau survival rate (SR) ikan Lele yang dipelihara dengan sistem akuaponik memiliki SR yang sangat tinggi yaitu 89.6-95.2\%.

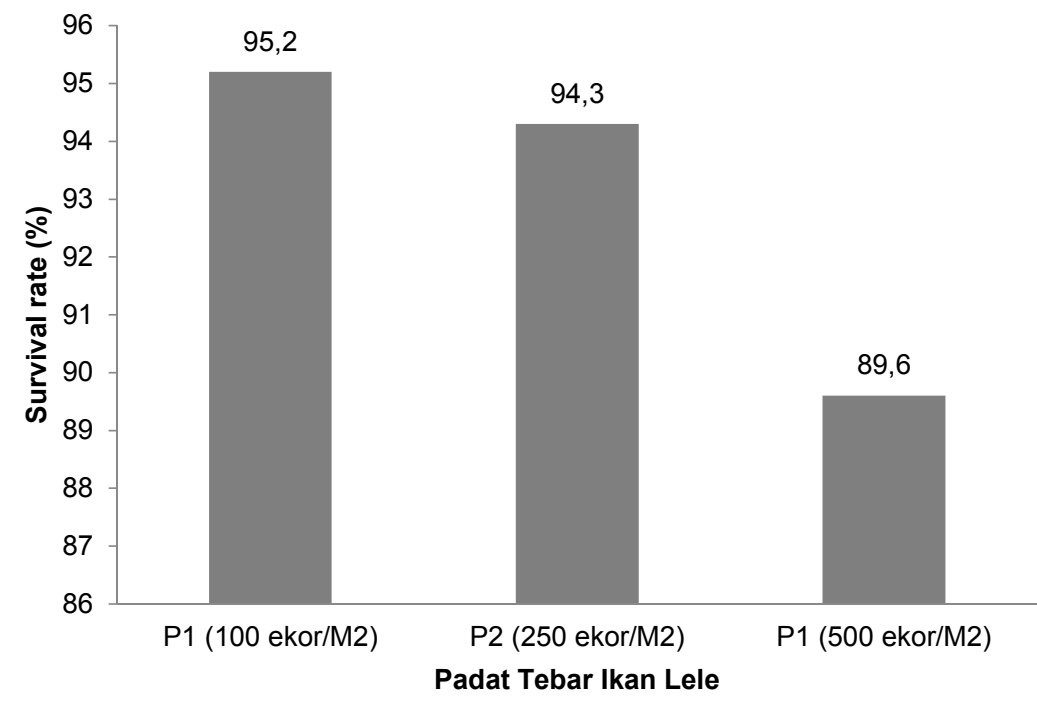

Gambar 1. Tingkat kelulushidupan atau survival rate ikan Lele sistem akuaponik

Semakin padat jumlah tebar ikan Lele, terlihat semakin rendah nilai SR yang didapatkan. Tingginya nilai SR tidak terlepas dari sistem akuaponik yang diterapkan, karena kandungan $\mathrm{NH}_{3}$, $\mathrm{NO}_{2}, \mathrm{NO}_{3}$ yang berbahaya dapat diserap dan distabilkan oleh tanaman kangkung untuk dijadikan sebagai nutrsi pertumbuhan tanaman.

\section{Pertumbuhan Kangkung}

Pemeliharaan ikan Lele dengan sistem akuaponik dinilai lebih menguntungkan karena selain dapat memanen ikan lele juga dapat memanen hasil tanaman. Pertumbuhan tanaman dipengaruhi oleh ketersediaan unsur hara sebagai pupuk pada media tanam. Tanaman Kangkung yang ditanam dengan sistem akuaponik memiliki pertumbuhan yang berbeda sesuai dengan perbedaan pada tebar ikan Lele.

Tabel 2. Pertumbuhan tanaman Kangkung sistem akuaponik dengan pada budidaya ikan Lele

\begin{tabular}{cccc}
\hline Perlakuan & Tinggi Tanaman (cm) & Lebar Daun $(\mathbf{c m})$ & Jumlah Daun (helai) \\
\hline $\mathrm{P} 1\left(100 \mathrm{ekor} / \mathrm{m}^{2}\right)$ & $29.2 \pm 2.12$ & $2.1 \pm 0.3$ & $16 \pm 2$ \\
$\mathrm{P} 2\left(250 \mathrm{ekor} / \mathrm{m}^{2}\right)$ & $32.6 \pm 1.83$ & $2.1 \pm 0.2$ & $21 \pm 2$ \\
$\mathrm{P} 3\left(500 \mathrm{ekor} / \mathrm{m}^{2}\right)$ & $37.2 \pm 2.51$ & $2.5 \pm 0.2$ & $24 \pm 1$ \\
\hline
\end{tabular}

Semakin tinggi pada tebar ikan Lele pada media tanam semakin mempercepat pertumbuhan tanaman Kangkung. Terlihat pada tabel 2 padat tebar $500 \mathrm{ekor} / \mathrm{m}^{2}$ memiliki nilai pertumbuhan terbaik, pertumbuhan tinggi tanaman $37.2 \mathrm{~cm}$, lebar daun $2.5 \mathrm{~cm}$, dan jumlah daun 24 helai.

\section{Pembahasan}

Salah satu cara meningkatkan hasil produksi ikan Lele yaitu dengan cara meningkatkan pada tebar per satuan meter kubik. Pada penelitian ini padat tebar yang digunakan adalah $100 \mathrm{ekor} / \mathrm{m}^{2}$, $250 \mathrm{ekor} / \mathrm{m}^{2}$, dan $500 \mathrm{ekor} / \mathrm{m}^{2}$. Peningkatan padat tebar ikan lele tidak hanya berpengaruh positif pada hasil produksi, namun disisi lain ada dampak negatif yaitu semakin tingginya kandungan

To Cite this Paper Prakosa, D, G., 2021 Pemanfaatan limbah kolam lele (clarias sp.) Sebagai pupuk organik dalam penerapan akuaponik. Samakia: Jurnal IImu Perikanan, 12 (2) : 170-174 
amoniak, nitrit, dan nitrat yang dapat memperburuk media budidaya ikan serta dapat berdampak pada tingkat mortalitas ikan yang cukup tinggi. Bahkan tidak jarang tingginya kandungan amoniak dapat menyebabkan kematian hingga $100 \%$ pada budidaya ikan Lele.

Media budidaya ikan Lele dengan sistem akuaponik memberi efek nilai positif dengan efek nilai kualitas air berada pada ambang batas normal (Tabel 2). Nilai normalitas tidak terlepas dari peran sistem akuaponik tanaman kangkung yang dapat menyerap kandungan senyawa kimia air seperti $\mathrm{NH}_{3}, \mathrm{NO}_{2}$, dan $\mathrm{NO}_{3}$ pada media budidaya ikan Lele. Ramadhani et al., (2020) mengungkapkan bahwa tanaman Kangkung memiliki sifat fitoremediator yang dapat menyerap limbah dan cemaran lingkungan, termasuk unsur hara pada media budidaya ikan.

Pada penelitian lain yang dilakukan oleh Ramadhani et al., (2020) limbah media budidaya ikan Lele memiliki berbagai unsur hara yaitu C-organik (0.169\%), Nitrogen $1.680 \%$, fosfor $2.380 \%$, dan kalium $1.390 \%$. Kandungan unsur hara yang terdapat pada media pemeliharaan ikan lele, seperti nitrogen akan dimanfaatkan oleh tanaman kangkung untuk meningkatkan fotosintesis dan selanjutnya akan meningkatkan pertumbuhan tanaman Kangkung. Menurut Nugroho et al., (2012) penerapan akuaponik pada tanaman Kangkung dapat meningkatkan pertumbuhan tanaman 23-25 $\mathrm{cm}$. Data yang ditampilkan pada Tabel 3 juga memperkuat dugaan tersebut, dimana semakin padat tebar ikan Lele juga berdampak semakin cepat pertumbuhan tanaman Kangkung hingga mencapai $37.2 \mathrm{~cm}$.

\section{KESIMPULAN}

Pemeliharaan ikan Lele dengan sistem akuaponik dengan tanaman Kangkung dapat menstabilkan kualias air dengan hasil pengamatan nilai $\mathrm{NH}_{3}, \mathrm{NO}_{2}, \mathrm{NO}_{3}, \mathrm{pH}$, dan $\mathrm{DO}$ berada pada ambang batas yang dibutuhkan ikan Lele. Tingkat survival rate tertinggi ikan Lele diperoleh pada P1 dengan padat tebar $100 \mathrm{ekor} / \mathrm{m}^{2}$ dengan $95.2 \%$, dan pertumbuhan tanaman Kangkung terbaik terlihat pada perlakuan P3 padat tebar $500 \mathrm{ekor} / \mathrm{m}^{2}$ (dengan rata-rata tinggi tanaman $27.2 \mathrm{~cm}$, lebar daun 2.5 $\mathrm{cm}$, dan jumlah daun 24 helai.

\section{DAFTAR PUSTAKA}

Nugroho, R.A., Pambudi, L.T., Chilmawati, D. dan Haditomo, A.H.C. 2012. Aplikasi teknologi aquaponic pada budidaya ikan air tawar untuk optimalisasi kapasitas produksi. Saintek Perikanan, 8 (1): 46-51.

Ramadhani, L.E., Widuri, L.I., Dewanti, P. 2020. Kualitas Mutu Sayur Kasepak (Kangkung, Selada, dan Pakcoy) dengan Sistem Budidaya Akuaponik dan Hidroponik. Jurnal Agroteknologi, 4 (1): 33-43 